\title{
O DISCURSO DE CREONTE NA ANTÍGONA DE SÓFOCLES
}

\author{
CREON'S DISCOURSE IN SOPHOCLES' ANTIGONE
}

\author{
Janio Davila de Oliveira \\ Universidade Federal de Santa Maria, Santa Maria, RS, Brasil
}

Resumo: O objetivo deste artigo é analisar o discurso da personagem Creonte, presente na obra Antígona, de Sófocles. Creonte ocupa o trono de Tebas após um período de guerra, fazendo uso de um discurso que preza pelo bem comum, mas que na progressão da peça vai se mostrando frágil e prepotente. Ao proclamar um edito que proíbe a inumação do corpo de Polinices, irmão de Antígona, causa um conflito entre leis positivas e leis naturais. Questionado por seu filho Hêmon e pelo adivinho Tirésias, o rei tebano apresenta uma lógica discursiva entremeada de paradoxos. Para estudá-los, usaremos neste ensaio como referenciais críticos François Ost, Aristoteles, Hegel, Kathrin H. Rosefield e George Steiner.

Palavras Chave: Discurso; Creonte; Antígona.

Abstract: The aim of this paper is to analyze the discourse of Creon present in Antigone by Sophocles. Creon takes the throne of Thebes after a period of war, using a discourse that values the common good of Thebes, although during the play it proves to be a fragile and arrogant. When proclaimed a law that prohibits the burial of Polinices, Antigone's brother, he causes a conflict between positives laws and naturals laws. When Creon is questioned for his son and for the fortune teller Tirésias, the Theban king presents a discursive logic interspersed of paradoxes. For this study, we will use as critical and theoretical references, François Ost, Aristoteles, Hegel, Kathrin H. Rosefield and George Steiner.

Keywords: Literary Criticism, Tyrannical Speeches, Sophocles, Antigone.

\section{Introdução}

A obra Antígona ${ }^{16}$, de Sófocles, narra a saga da filha de Édipo, que volta para Tebas após a morte do pai em Colono. Ao retornar a sua terra, Antígona encontra um cenário de guerra causado por seus dois irmãos, Etéocles e Polinices. Após a morte de Édipo, os dois irmãos haviam feito um acordo de se revezarem no trono de Tebas, cada um tendo direito a um ano de reinado, começando por Etéocles. Porém, transcorrido o primeiro ano, Etéocles se negou a entregar o trono para o irmão, causando, assim, a guerra. Polinices, em contrapartida, reuniu um forte exército em Argos e atacou Tebas. Nesta guerra os dois irmãos morrem um pela mão do outro, e Tebas acaba resistindo à invasão, ponto no qual tem início a peça de Sófocles.

${ }_{16}$ A Antígona, de Sòfocles, é a terceira peça da chamada Trilogia Tebana, composta por Édipo Rei, Édipo em Colono e por Antígona. Apesar de vir depois das outras duas peças na ordem cronológica da história. Antígona foi a primeira delas a ser escrita por Sófocles, tendo sido representado pela primeira vez em 441 a.C. em Atenas 
Creonte, irmão de Jocasta e tio dos filhos de Édipo, assume a sucessão do trono, que passa a ser seu por direito, e impõe um decreto proibindo que seja dada sepultura ao corpo de Polinices como castigo por sua traição ${ }^{17}$. Porém, era crença entre os gregos que o morto que não fosse sepultado ficaria com a alma a errar pela terra ${ }^{18}$. Esta contradição acaba por gerar o conflito da tragédia. Antígona não aceita o decreto e resolve, mesmo contra as ordens de Creonte, sepultar seu irmão.

Durante a ação, Antígona é flagrada por um guarda ao atirar um punhado de terra sobre o corpo do irmão, aquele a entrega a Creonte, que a condena à morte. A atitude autoritária do soberano é questionada durante a peça por seu filho Hêmon, pelo sábio Tirésias, e claro, pela própria Antígona. Creonte não cede. Ao final, a inflexibilidade de Creonte acaba causando a morte de Antígona, de Hêmon, e de sua esposa, Eurídice.

O conflito entre Antígona e o monarca tebano se constitui, para Hegel, como a essência do gênero trágico: duas forças legítimas e moralmente justificadas que se enfrentam, cerne da estrutura dramática grega. Na peça de Sófocles, Antígona defenderia as leis naturais, enquanto Creonte, o direito positivo que rege a vida pública e assegura o bem da comunidade (HEGEL, 1993, p. 656), numa oposição que se tornou clássica nos estudos helenistas.

O objetivo deste artigo é analisar o discurso de Creonte e apresentar uma interpretação que possibilite o melhor entendimento da postura discursiva do personagem. Para isso, o corpus de pesquisa escolhido para a análise será composto de trechos do discurso que julgamos ocupar um papel chave dentro da obra. A tradução escolhida foi a de Mario da Gama Kury, presente no livro A Trilogia Tebana. Usaremos como referenciais os teóricos François Ost, Aristoteles, Hegel, Kathrin H. Rosefield e George Steiner, entre outros.

\section{O discurso de Creonte e sua interpretação crítica}

Na primeira fala de Creonte na peça, ele fará o seu discurso de posse. Neste ponto já sabemos sobre o decreto proibindo que seja dada sepultura a Polinices. Também já é sabido que Antígona pretende desobedecer ao soberano e dar sepultura a seu irmão. Assim, Creonte apresenta o discurso de alguém disposto a tomar as decisões pensando no melhor para a cidade, um soberano preocupado com o bem comum de seus subordinados. Também é

17 Fustel de Coulanes, no livro $A$ cidade Antiga, escreve: "Nas cidades antigas, a lei atingia os
grandes culpados com um castigo considerado terrivel, a privação da sepultura Punia-se assim a
própria alma, e lhe infligiam um suplicio quase eterno". (COULANGES, 2009, p.27)
18 "Toda a antiguidade estava convencida de que, sem a sepultura, a alma era miserável, e que pela
sepultura se tornava feliz para sempre Não era para exibição da dor que se realizava a cerimônia
fúnebre, mas pelo repouso e pela felicidade do morto." (COULANGES, 2009, p.26) 
evidente na fala do rei, a preocupação em relação aos "amigos" e "inimigos" da pátria.

\author{
CREONTE \\ Se alguém, sendo o supremo guia \\ do estado, não se inclina pelas decisões \\ melhores e, ao contrário, por algum receio \\ mantém cerrado os seus lábios, considero-o \\ e sempre considerarei o mais ignóbil \\ das criaturas; e se qualquer um tiver \\ mais consideração por um de seus amigos \\ que pela pátria, esse homem eu desprezarei. \\ Pois eu- e seja testemunha o grande Zeus \\ onividente - não me calaria vendo \\ em vez da segurança a ruína dominar \\ o povo, e nunca trataria os inimigos \\ de minha terra como se fossem amigos \\ (2011, p. 208).
}

$\mathrm{Na}$ fala de Creonte, é necessário destacar algumas palavras e expressões que serão usadas por ele para sustentar seu decreto até que as desgraças mostrem a ele seus equívocos. Primeiramente, destaca-se a expressão "decisões melhores". Os principais acontecimentos no decorrer da trama passarão pela ótica daquilo que Creonte julga melhor. Não menos importante é a oposição entre "pátria" e "amigos". No primeiro momento da fala, estas palavras aparecem como opostas. Creonte entende que pátria está de um lado, amizade de outro, sendo a escolha de uma delas demarcadora de ruína ou de segurança para a cidade de Tebas. Na parte final da fala, a palavra "amigos" aparecerá com sentido positivo, pois agora, estará em oposição à expressão "inimigos de minha terra".

Nesta fala introdutória de Creonte, há um governante cuja preocupação maior é manter a cidade em paz e livre de problemas. O seu discurso indica que toda a decisão tomada será pensando exclusivamente no bem de Tebas. Ao dizer que qualquer pessoa deva ter mais consideração pela pátria do que por seus amigos, sugere que suas atitudes também serão sempre em favor da pátria. Porém, no decorrer da peça, a sua inflexibilidade e arrogância não deixarão que essas primeiras palavras se façam possíveis. Estas palavras também mostram uma excessiva preocupação de Creonte por saber quem são os inimigos e quem são os amigos da sua pátria. Conforme a autoridade de Creonte é questionada, ele gradativamente encontra mais inimigos do que esperava. Segundo François Ost, tudo para Creonte se reduzirá a oposição amigo/inimigo, a ponto de englobar até os deuses nesta dicotomia ao sugerir Hades como suspeito de simpatia pelos traidores (2004, p.199). Isso fica evidente quando Creonte manda que Antígona vá suplicar ao deus dos mortos, o único que ela venera, para não perecer (2011, p. 236). 
A primeira vez que a ira de Creonte se manifesta na peça, justamente quando seu discurso da mostras de inflexibilidade, é quando recebe do guarda a notícia da tentativa de sepultamento do corpo de Polinices. O acontecimento faz parte do primeiro episódio. Um guarda vem anunciar que seu edito real foi descumprido e que o corpo de Polinices amanheceu coberto com um pouco de terra. Após o guarda terminar o relato, o Corifeu pergunta para o rei: "Meu coração, senhor, indaga há muito tempo/ se esse acontecimento não se deve aos deuses (1990, p. 208). Então, o soberano responde, mostrando sua fúria pela primeira vez:

\section{CREONTE}

Cala-te logo, antes que cresça minha cólera
com tua fala, salvo se queres mostrar
senilidade e insensatez ao mesmo tempo.
Ė insuportável escutar-te quando dizes
que os deuses podem ter cuidado do cadáver.
Seria por inusitada recompensa
a um benfeitor que lhe dariam sepultura,
a ele, que chegou para queimar seus templos
cercados de colinas e os tesouros sacros
e apara aniquilar a sua terra e leis?
(2011, p. 212).

Neste fragmento, dois campos semânticos são de fundamental importância: o primeiro é o das palavras que estão relacionadas à religião e à família, enquanto o segundo apresenta palavras que estão relacionadas ao estado e às suas leis. No primeiro grupo, estão "deuses", "cadáver" e "sepultura". Do segundo grupo farão partes as palavras: "recompensa", "tesouros", "terra" e "leis". A palavra "leis" aparecerá durante todo texto, tanto na fala de Creonte, quanto na fala de Antígona. Cada um deles defenderá o seu ponto de vista, usando como argumento uma legislação. Creonte defenderá a do estado, Antígona, a divina.

A análise das palavras de Creonte deixa claro que o soberano, em momento algum, despreza a importância das divindades ou as coloca abaixo do poder estatal. Pelo contrário, ele parece se preocupar em não contrariar as vontades divinas. $\mathrm{O}$ grande problema é que segundo a lógica de Creonte é impossível que sua vontade como governante não coincida com a vontade dos deuses. Assim como Édipo um dia se julgou o senhor da sabedoria, agora é Creonte quem não cogita a possibilidade de estar errado, e de fato, a lógica literária da obra não nos permite afirmar que está, uma vez que seu argumento político se revela lógico.

Como se trata de uma tragédia clássica e não de uma novela romântica ou de uma peça shakespeariana, onde há algum tipo de luta entre um herói modelar e um malfeitor revestido de ambiguidades morais, não 
podemos falar de Creonte como se fala de um vilão aos moldes modernos e nem reduzir Antígona a uma heroína virtuosa ou idealizada. Para entendermos estes anacronismos ao trabalhar a peça é sempre oportuno revisitarmos a Poética, de Aristóteles.

Segundo Aristóteles, os fatos representados em uma tragédia devem excitar o temor e a piedade nos espectadores. Para que isso ocorra, a tragédia não deve mostrar pessoas justas passando da felicidade ao infortúnio, pois isso não produz temor e nem pena, apenas indignação. Também não convêm homens maus passando do crime à felicidade, pois isto não inspira nem pena, nem temor. Outra representação que não pode ser apresentada é a de um homem perverso passando da felicidade ao infortúnio, o que, igualmente, não produz temor ou piedade. Resta então, a posição intermediária: a do homem que não é mau nem perverso, mas que cai no infortúnio em função de algum erro que cometeu (2005, p. 31-32).

Os comentários aristotélicos a respeito do ideal herói-trágico revelam um Creonte mais próximo da justiça do que da injustiça, afinal, foi Polinices quem liderou o ataque à Tebas pondo a cidade em risco. Em vista disso, como poderia Creonte não lhe aplicar a devida punição? O problema trágico, neste caso, é o fato de o culpado estar morto. Então, teria Creonte o poder de julgar e aplicar pena a alguém que agora pertence ao reino dos mortos? Sobre esse problema, François Ost afirma:

O princípio de interdição de inumar os traidores da pátria poderia ter sido mantido, mas demonstrando indulgência, dadas as circunstancias, em relação à pessoa de Antígona. Uma casuística da regra e da exceção, típica da racionalidade jurídica, poderia assim ter-se instaurado, permitindo certamente, se não a solução das antinomias, pelo menos que sua tensão fosse provisoriamente aceitável. Heróis trágicos, e portanto talhados em blocos, nem Creonte nem Antígona aceitarão, porém, uma tal solução, ainda mais que, como veremos, a justiça de Creonte carece das mais elementares exigências de imparcialidade. (2004, p. 209)

A possibilidade apresentada por Ost, além de chocar-se com a inflexibilidade dos protagonistas, choca-se com a perspectiva jurídica unidimensional de Creonte. Esta perspectiva se reduz a uma aplicação compulsiva da lei sem levar em conta qualquer exceção. Apesar de Creonte ser o juiz deste caso, na leitura de Ost as palavras "indulgência" e "casuística" não deveriam aludir a este universo conceitual. Uma exceção representaria fraqueza na visão do soberano. Quanto a analisar o caso a procura de uma possível casuística, como levar em consideração a questão familiar, por exemplo, também não é cogitado pelo rei. Qualquer coisa que não seja a aplicação dura da lei representa a tão temida anarquia ${ }^{19}$. Outro termo usado por Ost e que

${ }^{19}$ No diálogo com Hêmon, onde reside o centro da discussão política da peça, Creonte expõe seu medo da anarquia: "Mas a anarquia é o mal pior;/ é perdição para a cidade e faz desertos/ onde 
está totalmente em oposição a Creonte é "imparcialidade". Creonte está julgando membros do seu genos e sabe que há implicações éticas nisso quando afirma que mesmo Antígona e Ismene, sendo filhas de sua irmã, não se livrarão do destino atroz a que ele as condenará (SÓFOCLES, 2011, p. 220). Como poderia Creonte julgar um caso envolvendo suas sobrinhas sem que sua imparcialidade seja ameaçada?

No segundo episódio ocorre o primeiro encontro entre os dois protagonistas, Antígona e Creonte ${ }^{20}$. Após ser flagrada pelo guarda, tentando novamente cobrir o corpo do irmão com terra, Antígona é levada à presença de Creonte e questionada pelo rei sobre o seu conhecimento em relação ao edito. Sua resposta é afirmativa. A irmã de Polinices, em nenhum momento do diálogo com o rei, mostra arrependimento ou tenta defender-se pelo desacato, ao contrário, mais uma vez ela irá afirmar que as leis dos deuses estão acima das leis humanas e que, portanto, ela tem convicção de que não cometeu nenhum crime, embora saiba que vai morrer ${ }^{21}$. Creonte entende a insubordinação de Antígona como um desafio:

\section{CREONTE}

Ela já se atrevera, antes, a insolências ao transgredir as leis apregoadas; hoje, pela segunda vez revela-se insolente ufana-se do feito e mostra-se exultante! Pois homem não serei - ela será o homem! Se esta vitória lhe couber sem punição! (2011, p. 220).

Destacamos aqui as palavras, "atrevera", "insolente" "ufana-se" e "vitória". Para Creonte, Antígona quer, com sua rebeldia, apenas desafiá-lo. Além do bem de Tebas, a punição de Antígona agora é tratada por ele como uma questão de honra, como se a não punição de Antígona representasse

existiam lares; ela é causadora/ de defecções entre as fileiras aliadas,/ levando-as à derrota." (SÓFOCLES, 2011, p. 230)

${ }^{20} \mathrm{Na}$ ótica de G. Steiner, a oposição entre Antígona e Creonte representa as cinco principais constantes do conflito próprio da condição humana. As oposições entre homem e mulher, velhos e jovens, social e individual, vivos e mortos, e por fim, entre os homens e os deuses. (2008, p. $257-$ 258)

${ }^{21}$ Antígona afirma ao ser questionada por Creonte se havia desobedecido às leis: "Mas Zeus não foi o arauto delas para mim,/nem essas leis são as ditadas entre os homens/pela Justiça, companheira de morada/dos deuses infernais; e não me pareceu/que tuas determinações tivessem força/para impor aos mortais até a obrigação/de transgredir normas divinas, não escritas,/inevitáveis; não é de hoje, não é de ontem,/é desde os tempos mais remotos que elas vigem,/sem que ninguém possa dizer quando surgiram./E não seria por temer homem algum,/nem o mais arrogante, que me arriscaria/a ser punida pelos deuses por violá-las./Eu já sabia que teria que morrer/(e como não?) antes até de o proclamares,/Mas, se me leva a morte prematuramente, /digo que para mim só há vantagens nisso"(SÓFOCLES, 2011, p. 219) 
sofrer uma derrota na sua condição de homem. O fato de Antígona não mostrar arrependimento pelo seu ato é entendido como ufanismo.

Não há, por parte de Creonte, o entendimento de que a transgressão de uma lei pode significar mais que uma simples insubordinação. Se a lei foi descumprida, há uma motivação, um desencontro de opiniões. Ele só entende o gesto de Antígona como um desafio. Assim, faz com que haja um deslize no seu discurso e uma questão de interesse público acaba se tornando, também, uma questão pessoal.

Kathrin Rosefield apresenta outro fator importante ao tratar do confronto entre Antígona e Creonte. A luta de duas dinastias pela sobrevivência. Segundo Rosefield, nos mitos anteriores a Sófocles, Antígona e Creonte descendem de duas dinastias distintas. Enquanto ela descende dos Lábdácidas, uma dinastia de reis, Creonte pertence a um ramo de conselheiros reais e regentes. Creonte e seus ancestrais, Menockeus e Oklasos assumem o poder apenas em situações emergenciais.

Segundo Rosenfield, a partir de Hölderlin, há um problema que subjaz às questões políticas e religiosas: com a morte dos irmãos, Eteocles e Polinices: a quem pertenceria o trono tebano, a uma nova linhagem reinante ou a um futuro filho de Antígona? Pelas leis da época de Sófocles, Creonte teria que casar Antígona, com seu parente mais próximo, no regime de epiclerado. O parente mais próximo de Antígona seria Hêmom, que teria que se mudar para o lar dela e não o contrário, como era a regra. Desta forma, o filho do casal seria descendente da linhagem dos Labdácidas e não da linhagem dos regentes. Devido ao fato de Hêmon ser o único filho de Creonte, a linhagem seria extinta. Segundo a autora, para

compreender o que está em jogo no enfrentamento de Antígona e Creonte, é preciso compreender o peso de pequenos sinais que Sófocles colocou nas falas de seus heróis - sinais estes que podem passar despercebidos para leitores que não conhecem bem os mitos antigos, os costumes e as instituições ou a língua da época clássica. (2002, p. 13-14)

Desta forma, se faz necessário levar em conta elementos que transcendem o texto. O público da Grécia antiga, espectador das tragédias, estava familiarizado com o mito. Assim, há elementos que escapam ao leitor moderno e que podem obscurecer algumas partes do texto. $\mathrm{O}$ texto de Sófocles, com suas ambiguidades e sutilezas, demanda de seu leitor cuidados para não cair em meros reducionismos.

Outro momento de grande tensão na tragédia é o diálogo entre Hêmon e Creonte, no terceiro episódio. Hêmon tenta trazer a razão para o debate e convencer seu pai a repensar a sua decisão. Ele assume uma posição respeitosa diante do pai, se apresentando já no começo como um "amigo" e não como um opositor. Mas Creonte com sua visão hierárquica e unilateral 
dos fatos desprezará os conselhos do jovem. Também é aqui, neste ponto, que teremos a grande discussão política da peça. Creonte reafirmará, diante dos questionamentos do filho, a sua posição de tirano.

CREONTE
[...]Se alguém transgride
as leis e as violenta, ou julgar ser capaz
de impingir aos detentores do poder,
não ouvirá em tempo algum meus elogios;
muito pelo contrário, aquele que entre os homens todos
for escolhido por seu povo, deve ser
obedecido em tudo, nas pequenas coisas,
nas coisas justas e nas que lhes são opostas
[...] A submissão, porém,
é a salvação da maioria bem mandada.
Devemos apoiar, portanto, a boa ordem,
não permitindo que nos vença uma mulher
(2011, p. 230).

As palavras do soberano deixam clara a sua visão de mundo, onde não há espaço para desobediências, questionamentos, ou desrespeito às hierarquias. Ao dizer que um governante deve ser obedecido em "tudo", Creonte deixa evidente que sua concepção de autoridade é estendida muito além do que deveria, a ponto de chegar ao Hades. As palavras "poder", "obedecido" e "submissão", reforçam este forte autoritarismo. Pode-se notar também a expressão "boa ordem", usada por Creonte em oposição à palavra "mulher", o que indica mais uma vez este significado de ameaça que Creonte enxerga no feminino.

O diálogo que começará no âmbito familiar e logo partirá para o debate político, torna-se praticamente inviável em certo ponto. Creonte passará a desqualificar os argumentos do filho, pois para ele, um filho deve obediência ao pai e isso é tudo. Nessa estrutura familiar e cultural, um filho não poderia estar certo e o pai errado, visto que o pai está acima na hierarquia social; neste caso, também, na hierarquia política. Creonte agirá assim em todos os seus diálogos: Hêmon é jovem e seu filho, Antígona e Ismene são mulheres, o coro é composto por anciãos e Tirésias é um adivinho que deve obediência ao governante. Da perspectiva de Creonte, tudo se resume a uma pré-estabelecida e pré-definida hierarquia, estando o tirano em seu topo.

Segundo Ost, Creonte criará um vazio ao seu redor. Enquanto em condições ideais a cidade deveria se reunir em torno de um centro vazio de poder, na Tebas de Creonte, onde reina a tirania, é o vazio que se cria em torno do poder concentrado na pessoa do chefe. Creonte reivindica um poder tão ilimitado que se estende ao ponto de mandar no injusto. (2004, p. 221)

Nota-se na fala de Creonte um fechamento total para qualquer relação dialética. Não existe troca, diálogo ou conselho. Para o tirano, existe 
apenas o soberano e os seus subordinados. O diálogo acaba com o fracasso da tentativa de Hêmon de intervir onde só existe a lógica da autoridade. Antes de sair de cena Hêmon não deixa de ironizar a obsessão do pai com os "amigos". "Guarda essa fúria para teus dóceis amigos" (1990, p. 229).

Caberá, por fim, a Tirésias abrir os olhos de Creonte e mostrar-lhe todo o mal que sua intransigência está causando, mas não sem antes sofrer duras acusações. Os altares estão todos poluídos pela "carniça" do cadáver de Polinices, os deuses já não escutam as preces e nem aceitam os sacrifícios da cidade e os pássaros soltam gritos estrídulos, após provar a gordura e o sangue de homem podre. Creonte mais uma vez não aceitará uma opinião contrária e, assim como acusou o guarda, acusará o sábio de ter se vendido por dinheiro.

\title{
CREONTE
}

\author{
Tu, ancião, e todos vós, fazeis-me o alvo \\ De vossas flechas, como arqueiros; não me poupa. \\ Também, agora, o teu poder divinatório. \\ Há muito tempo a atua confraria explora-me \\ E faz de mim o seu negócio; prossegui, \\ Lucrai; negociai, se for vossa vontade, \\ o electro lá de Sardes ou da índia o ouro, \\ mas aquele cadáver não enterrareis; \\ (2011, p. 244-245).
}

É interessante notarmos o rumo que toma o discurso de Creonte após ter a sua inflexibilidade atacada pelo adivinho. Ao voltar a se dirigir a Tirésias, o soberano já não usa o respeitoso "velho Tirésias". Antes, dirige-se a ele como "Tu, ancião". Tirésias já não representa mais a sabedoria ou a vontade dos deuses, agora é apenas um "ancião". Essa necessidade de definir o lugar do "outro" está presente durante todo discurso do soberano, a necessidade de colocar cada pessoa em seu lugar se revela nas tantas vezes que ele lembra que Antígona é uma mulher, assim como desprezará os conselhos do seu filho usando como um dos argumentos o fato de Hêmon ser um jovem

Mais uma vez o tirano acredita ser vítima de uma conspiração. No segundo episódio, o acusado foi o guarda, agora, é o adivinho quem é apontado como traidor e venal, atitude esta, que sabemos ser normal em governos autoritários, que por governarem contra a vontade do povo, nutrem um constante sentimento de ameaça. Esse medo de uma conspiração e o sentimento de estar ameaçado reforçam ainda mais o seu autoritarismo. Tudo e todos estão contra ele. Tudo se torna uma ameaça. O dinheiro passa a representar perigo por ter o poder de corromper os homens.

Porém, diferentemente do episódio em que o guarda é acusado, aqui, a acusação se estende a todos ("Tu, ancião, e todos vós, fazeis-me o alvo"), o discurso de Creonte já está totalmente desestabilizado e a sua insegurança faz como que ele veja apenas conspirações para atingi-lo. Neste momento, a 
distinção entre amigos e inimigos, tão presente nas suas falas anteriores, parece não fazer mais sentido. Para Creonte, todos se transformaram em inimigos.

Essa dureza e desconfiança no discurso de Creonte, somada a sua obsessão de saber quem são os amigos e inimigos de Tebas, faz sentido quando parte de um governante que está assumindo o poder após ter pegado em armas para defender a cidade. Creonte está saindo de uma guerra, e a guerra ainda está em seu discurso: Steiner assinala:

O que importa é que Creonte entra em cena impelido pelos ventos da guerra. É à carnificina do dia e da noite anteriores que deve a sua soberania sobre a cidade salva. Os agressores de Argos estão ainda, por assim dizer, no horizonte. O discurso de Creonte, com a sua grandiloquência e auto-exaltação metálicas, com a sua alternância impressionante entre a inércia das fórmulas sentenciosas e as ordens peremptórias, tem por pano de fundo que o faz vibrar o fragor do combate corpo a corpo e a inquietante estranheza de sua brusca interrupção. (2008, p. 244)

É necessário entender que Tebas está saindo de uma guerra civil. Uma guerra que exigiu a vida de seu filho - Creonte sacrificou seu filho Megareu para que Tebas vencesse os agressores argivos. A insubordinação de um de seus filhos causou grande destruição à cidade, portanto, a disposição de Creonte para punir infratores e rebeldes, naturalmente, tem muita força. $\mathrm{E}$ num novo governo que acaba de assumir o poder após uma situação assim, é de se esperar que haja uma grande desconfiança em relação a quem confiar.

Após a saída de cena de Tirésias e depois de ser alertado pelo Corifeu sobre sabedoria do adivinho, Creonte passa a entender os males que poderiam ser causados por seus excessos e ele próprio decide ir libertar Antígona.

Irei imediatamente! E vós, Criados,

Marchai. Marchai, presentes e também ausentes,

Depressa, até o lugar por todos conhecido,

Portando em vossas mãos a ferramenta própria!

Já que mudou de rumo de rumo a minha opinião,

Irei soltar Antígona, eu que a prendi.

Agora penso que é melhor chegar ao fim

da vida obedecendo às leis inabaláveis

(2011, p.249).

É importante atentarmos para as palavras usadas por Creonte ao perceber sua imprudência. A pressa torna-se evidente no seu discurso. É preciso correr para evitar uma catástrofe maior. "Irei imediatamente", "Marchai, marchai" e "depressa" são palavras ditas por ele no desespero de correr atrás do tempo. Mas já é tarde. Antígona já se suicidou e junto com ela o seu filho Hêmon. Eurídice, sua esposa, ao saber dos acontecimentos, também tira a própria vida. Segundo François Ost, Creonte está atrasado mais 
uma vez, como se as coisas lhe escapassem e ele não tivesse domínio sobre os acontecimentos. Assim como a proclamação solene do edito diante do coro veio só depois da transgressão de Antígona, também só fica convencido do seu erro demasiado tarde (2004, p. 230).

Creonte cedeu às "leis inabaláveis" defendidas por Antígona. Mas não cedeu pelo debate ou pela persuasão. É somente após ver a ruína dominando Tebas que sua opinião mudará de rumo. Se Creonte acaba caindo de forma brutal e deixando o estado praticamente sem herança, não é pelas virtudes do diálogo ou pelo poder persuasivo da razão, mas quando a relação de forças, a única que ele entende, lhe tornou desfavorável a partir do momento em que os deuses manifestaram desaprovação (OST, 2004, p. 221).

A análise dos fatos expõe que a dureza das palavras de Creonte mostra a sua preocupação com o risco de uma nova insubordinação. Essa preocupação o leva a afirmar que desprezará qualquer homem que tiver mais consideração por seus amigos do que pela pátria. Desta forma, Creonte é coerente com suas palavras ao impor o decreto, afinal, um dos irmãos defendeu a pátria, o outro a atacou. Seria justo que os dois recebessem as mesmas honras? $\mathrm{O}$ argumento de Creonte é válido. O rei também mostra coerência ao condenar Antígona. Qual seria o efeito de uma transgressão praticada contra um governo que acaba de assumir?

Mas essa preocupação de Creonte em descobrir traidores, somado ao seu medo do caos e da anarquia, faz com que ele não confie no julgamento de mais ninguém. Todos que aparecem para tentar dialogar com o rei, ou são desqualificados por ele, ou são acusados de traição. O seu discurso passa a ser grosseiro. Os seus argumentos, antes apenas duros, agora são prepotentes e arrogantes, as suas palavras se transformam em demonstrações de poder e a inevitável insegurança emerge delas. Desta forma, Creonte falha ao não expandir sua visão jurídica e política durante a progressão dos acontecimentos. Reduzindo o caso à simples aplicação da lei, o rei não consegue entender a complexidade da antinomia e acaba por tratá-la de forma inflexível. Apesar de seu discurso inicial ser coerente com o momento, Creonte não tem a habilidade suficiente para ver além das dicotomias.

\section{Considerações finais}

Diante do exposto, podemos considerar que, apesar da arrogância e inflexibilidade no discurso de Creonte, não é possível afirmar que seus argumentos políticos não sejam lógicos. No primeiro episódio, Creonte afirma que seu dever é tomar as "decisões melhores" para o bem de Tebas. E logo no dia de sua posse ele já encontra uma difícil decisão a ser tomada, afinal, independente de sua escolha, haverá abalo na ordem da cidade. 
Porém, durante a progressão da peça, Creonte mostra não estar aberto ao diálogo. O seu autoritarismo é reforçado pela sua insegurança, seu medo de conspirações. A obsessão em fazer com que a lei seja cumprida e os infratores penalizados não lhe permite enxergar as razões que movem os outros personagens. Apesar das sutis sugestões do coro, das críticas de Antígona, Ismene e seu filho, Hemon, Creonte só enxerga a ruína que ameaça Tebas quando é alertado por Tirésias sobre os males que estão acontecendo em Tebas. Mas isso ocorre tarde demais. As fatalidades já foram consumadas. Diferentemente das Eumênides, de Ésquilo, em Antígona as antinomias não foram solucionadas pelo diálogo. Aqui a razão jurídica e a persuasão perderam para a prepotência e inflexibilidade do tirano.

Recebido em 15 de Junho de 2013. Aceito em 09 de Agosto de 2013.

\section{REFERÊNCIAS}

ARISTÓTEles. HORÁCIO. LONGINO. A Poética Clássica. São Paulo:

Cultrix, 2005.

COULANGES, Fustel de. A Cidade Antiga. São Paulo: Martin Claret, 2009;

HEGEL, G.F.W. Estética. Lisboa: Guimarães Editores, 1993;

OST, François. Contar a lei: as fontes do imaginário jurídico. São Leopoldo:

Unisinos, 2004.

ROSENFIELD, K. H. L. Sófocles \& Antígona. Rio de janeiro: Jorge Zahar Ed., 2002.

STEINER, George. Antígonas. Lisboa: relógio D’Água,2008.

SÓFOCLES, A trilogia tebana: Édipo Rei, Édipo em Colono, Antígona. Trad. Mario da Gama Kury. Rio de Janeiro; Editora Jorge Zahar, 2011.

96 fragmentum, N. 38, Vol. 1. Laboratório Corpus: UFSM, Jul./ Set. 2013 